a natural effort of the disease to allow more room for the fluids to collect, and had caused a little dilatation of the os uteri. Knowing the life of the patient to be in jeopardy, the first thing $I$ did was to puncture the membranes, in order to extract the fotus; this I found to be impracticable. She suddenly sank, and died at five minutes before 8 . About 20 minutes after 8 , feeling a distinct sensation of warmth, and, as I imagined, of throbbing, over the region of the uterus alone, I was led to ask the husband's consent before commencing the Crsarean operation. The child, by-the-by, had been felt by the mother in the course of the day. Making an incision through the parietes of the abrlomen, about an inch below the nm. bilicus, and carrying it along the linea alba to the same distance from the symphisis pubes, I exposed to view the aterus, with no protrusion of intestine. The former I opened, longitudinally, and at the fundus found that the placenta was closely adherent, which I divided, and from which a large quantity of blood was effused. However, I soon extracted the foetus, but life was extinct.

On referring to a late volume of ThE LaNCET, I observe it is there stated, from "Siebold's Journal of Midwifery," that in cases of a similar nature, the operation had been frequently had recourse to recently after the mother's death. Mr. Huack, after the lapse of half an hour; Dr. Bold, after one hour and a half; Dr. Schild even after eight hours; but in all the cases the children were extracted dead. Now, in the instance related by me, the period that elapsed from the death of the mother to the commencement of the operation was 25 minutes; and the failure, in my humble opinion, seemed to arise from the sudden evacuation of a large quantity of blood in cutting through the placenta, which was of vital importance to the already weak foetus, inasmuch as the arterial circulation of the mother had ceased for some time, and a loss of blood, however small, would, in all probability, have seriously affected it. I am, Sir, yours, \&.,

Romney Terrace, Westminster, J. C. AtKinson. Jan. 24, 1839.

\section{EFFECTS OF ALCOHOLIC DRINKS ON MOTHERS AND INFANTS.}

\section{To the Editor of The LANCET.}

StR :-I have resided in Ramsgate during nearly eight years, and have in that time attended 1,127 midwifery cases, and bave invariably found that, other circumstances being equal, those mothers who never tasted malt liquors, wine, or spirits, during and subsequent to the period of labour, have had the easiest labours, the earliest reco- veries, and the best health afterwards. Nay, more, I know several mothers who never could nurse their children, under the ale and porter system, without suffering greatly in health, but who, after relinquishing the use of those baneful stimulants, have experie enced a perfect freedom from disorder during the period of lactation. Nor was this all. The offspring of such mothers have enjoyed an unprecedented immunity from disease also.

That some females do not feel their health disordered whilst using those drinks, I am ready to admit, and that their tender infants, also, may escape; for a time, with impunity, is certain, but that both mother and child suffer more or less, in proportion to the quantity of these drinks taken by the mother, at a remote period, if not at the immediate time, is to me as certain as that $I$ am now writing. Nor do I see how it can be otherwise, ac. cording to the laws which govern the animal economy. Let any man in extensive practice, any man who is accustomed to reflect, review the state of health of the great majority of ale and porter drinking mothers during and after the period of child-bearing, and then say whether their health is what fit should be had they lived according to nature's dictates. In affirming that it is not, the mass of disease that presents itself amongst this, the better part of created beings, strongly confirms the assertion. I have under my own eye many mothers who are experiencing the ill effects of the moderate (not the immoderate) use of these falsely. denominated "strengthening" beverages, in the form of liver and stomach complaints, skin diseases, asthma, dropsy, \&c., and every impartial and observant member of the profession must have noticed similar results. Thousands of children are annually cut off by convulsions, \&c., from the effects of these beverages, acting through the mother.

Strong drinks excite a feverish state of the body, and create an artificial thirst, $-a$ thirst which is not expressive of any real want of the constitution, but a certain proof that the want does not exist. The greater the craving for them, under these circum. stances, the more certain we may be that they are not needed, and that they will cause positive mischief to both mother and child. The constitutions of both are stimu* lated beyond what nature ever intended that they should be. The laws which govern the animal economy are positively infringed, and it is impossible that either mother of child can escape the penalty of that infringe. ment. Both will suffer to a certainty in some shape or other; if not immediately, at a future period. I am, Sir, your very obedient servant,

A. Courtenay, Surg, R.N.

Ramsgate, Jan, 18th, 1840. 